\title{
Adsorption of phosphate at the aluminum (hydr)oxides-water interface: Role of the surface acid-base properties
}

\author{
Yang Xiaofang ${ }^{a}$, Wang Dongsheng ${ }^{\mathrm{a}, *}$, Sun Zhongxi ${ }^{\mathrm{b}}$, Tang Hongxiao ${ }^{\mathrm{a}}$ \\ ${ }^{a}$ Research Center for Eco-Environmental Sciences, Chinese Academy of Sciences, Beijing 100085, China \\ ${ }^{\mathrm{b}}$ Department of Chemistry and Chemical Engineering, Jinan University, Jinan 250022, China \\ Received 17 May 2006; received in revised form 28 September 2006; accepted 13 October 2006 \\ Available online 20 October 2006
}

\begin{abstract}
In this paper, the adsorption of phosphate on two crystallized aluminum oxides, pseudo-boehmite (pseudo- $\gamma-\mathrm{AlOOH})$ and $\alpha-\mathrm{Al}_{2} \mathrm{O}_{3}, \mathrm{was}$ studied. The adsorption experiments were carried out in $0.01 \mathrm{M} \mathrm{KNO}_{3}$ solutions at $\mathrm{pH} 4$ and 6 , respectively. Adsorption densities were calculated to evaluate the phosphate adsorption affinity for the two aluminum oxides. To better understand the effect of surface properties on the adsorption behavior of phosphate, the surface structure and properties were investigated with X-ray diffraction, $\mathrm{N}_{2}$ adsorption-desorption, electron microscope observation and surface acid-base titrations. The results from adsorption isotherms showed that at both $\mathrm{pH} 4$ and 6 , pseudo- $\gamma$ - $\mathrm{AlOOH}$ exhibited greater adsorption capacity than $\alpha-\mathrm{Al}_{2} \mathrm{O}_{3}$. For both pseudo- $\gamma-\mathrm{AlOOH}$ and $\alpha-\mathrm{Al}_{2} \mathrm{O}_{3}$, the adsorbed amount of phosphate at $\mathrm{pH} 4 \mathrm{was}$ higher than that at $\mathrm{pH}$ 6. Adsorption density calculation indicated that $\alpha-\mathrm{Al}_{2} \mathrm{O}_{3}$ had greater affinity for phosphate than pseudo- $\gamma$-AlOOH. Information gained from examinations of surface properties revealed that the specific surface area played an important role on adsorption capacity, while the acidity of surface aluminol groups evaluated from acid-base titration curves contributed more to adsorption affinity and consequently the adsorption density. (C) 2007 Elsevier B.V. All rights reserved.
\end{abstract}

Keywords: Pseudo-boehmite; $\alpha-\mathrm{Al}_{2} \mathrm{O}_{3}$; Surface acid-base properties; Phosphate; Adsorption

\section{Introduction}

Most minerals in natural soils and aquatic environments contain aluminum hydroxides and oxides, and various active aluminas are widely used as adsorbent and catalyst support in industrial processes [1]. Thus the knowledge of aluminum (hydr)oxide's structure and possible interactions in aqueous solution are of great importance. Although the physicochemical reactions at the surface of metal (hydr)oxides are complicated, it is well established now that the properties of metal (hydr)oxides surfaces in water, including surface charge and adsorption capacity, are determined by the nature and population of surface functional groups and the absorbates [2]. The aluminum (hydr)oxides with large amounts of surface active sites (higher surface area and low-crystalline) are more active than the wellcrystallined (hydr)oxides with lower surface area. Moreover, the acidity of surface aluminol groups plays an important role in the

\footnotetext{
* Corresponding author. Tel.: +86 1062849138 ; fax: +86 1062923543.

E-mail address: wgds@ @rcees.ac.cn (D. Wang).
}

adsorption properties of aluminum (hydr)oxides. Madsen and Blokhus [3] found that $\alpha-\mathrm{Al}_{2} \mathrm{O}_{3}$ had a greater affinity for benzoic acid than $\gamma$-AlOOH due to their mineralogical structure difference. Persson et al. [4] examined the adsorption of phthalate on aged $\gamma-\mathrm{Al}_{2} \mathrm{O}_{3}$ and boehmite, and pointed out that aged $\gamma-\mathrm{Al}_{2} \mathrm{O}_{3}$ had a greater adsorption capacity than boehmite because of aged $\gamma-\mathrm{Al}_{2} \mathrm{O}_{3}$ had a relatively smaller $\mathrm{p} K_{\mathrm{a} 2}$ value.

Phosphorus is a nutrient element for plant and algal growth and is critical for the eutrophication in surface waters. The adsorption-desorption of phosphate on aluminum hydroxides and oxides has been the subject of intense study for decades [5-10]. Some of the studies aimed at a better understanding of the adsorption mechanisms of strongly bound anions on aluminum (hydr)oxides. The affinity of phosphate for aluminum oxides depends on the phosphate's complexing capacity, which controls the binding process to the surface by ligand-exchange reactions, and the attractive or repulsive electrostatic field of the charged surface [11]. However, it is difficult to make comparisons among these studies because of differences in adsorbent and kinetics of adsorption. Diversity among aluminum (hydr)oxide adsorbents is caused by the differences in the crystal structure, crystallinity, 
particle shape and specific surface area. Various adsorption systems could have different phosphate adsorption affinity and capacity, although the intrinsic adsorption mechanisms may be similar.

Therefore, the aim of this article was to get some insights into the effect of surface properties on the phosphate adsorption by comparing the adsorption of phosphate on two different aluminum oxides under the same experimental conditions $(0.01 \mathrm{M}$ $\mathrm{KNO}_{3}, \mathrm{pH} 4 / \mathrm{pH}$ 6). The study was carried out by measuring phosphate adsorption isotherms for two aluminum oxide samples and by performing surface acidity estimation. A relationship between surface properties and the phosphate adsorption affinity was proposed.

\section{Materials and methods}

\subsection{Characterization of samples}

The two aluminum oxide powders obtained from Shandong Aluminum Corporation (SALCO, China) were characterized by means of a PaNalyfical X'pert Pro MPD X-ray diffractometer using $\mathrm{Cu} K \alpha$ radiation. The specific surface area was measured by the $\mathrm{N}_{2}$ /BET method (Micromeritics, ASAP 2000). Particle morphology and shapes were observed by a transmission electron microscope (TEM) (Hitachi, H-7500). The apparent particle size distribution in aqueous suspension was determined by a particle size analyzer (Malvern, Mastersizer 2000).

The electrophoretic mobility of the particles in $\mathrm{KNO}_{3}$ solutions were measured by a microelectrophoretic zeta-potential analyzer (Malvern, Zetasizer 2000). The solubility of the samples was determined by batch experiments. The alumina suspensions with the same composition as that in the titration and phosphate adsorption experiments were prepared and the suspension $\mathrm{pH}$ between 3 and 10 was adjusted by adding $\mathrm{HNO}_{3}$ or $\mathrm{KOH}$ to reach the given value. After contact during several hours (simulating the same contact time as with titration and adsorption) at various given $\mathrm{pH}$, the concentrations of aluminum in the supernatant solutions were measured by the ICP-OES (Perkin-Elmer, OPTIMA 2000).

All solutions were prepared using deionized water and all chemicals used were of analytical reagent grade.

\subsection{Surface potentiometric titration}

The measurement of surface proton charge of the two aluminum oxides was carried out by acid-base potentiometric titrations [12-14]. The continuous potentiometric titration was performed under $\mathrm{CO}_{2}$-free condition using $\mathrm{KNO}_{3}$ as background electrolyte at different ionic strength $(0.1,0.01$ and $0.001 \mathrm{M}$, respectively) and at a constant temperature of $25^{\circ} \mathrm{C}$, which was maintained by immersing the sample suspension vessel in a water bath thermostat. The titration process was carried out using a Metrohm automatic system (716 DMS), with a combination $\mathrm{pH}$ electrode calibrated with standard buffer solutions to check the $\mathrm{pH}$ response. Before titration the solid samples were equilibrated with electrolyte solutions for an hour, gently stirring under a continuous stream of purified nitrogen gas. Then the acid or base $\left(\mathrm{HNO}_{3}\right.$ or $\left.\mathrm{KOH}\right)$ was added to the suspension using the DET program method (Dynamic Equivalence point titration).

The titration was performed with acid and base addition from the original $\mathrm{pH}$ down or up to $\mathrm{pH} 4$ and 10 , respectively.

\subsection{Phosphate adsorption experiment}

The phosphate adsorption was performed by batch experiments. Adsorption was studied by adding $100 \mathrm{mg}$ of the adsorbent powder to $25 \mathrm{~mL} \mathrm{KNO}_{3}$ solution in $50 \mathrm{~mL}$ flasks. After $1 \mathrm{~h}$ pre-hydration of the surface, various amounts of $\mathrm{KH}_{2} \mathrm{PO}_{4}$ stock solution were added to obtain the initial target phosphate concentration. The $\mathrm{pH}$ was adjusted with $\mathrm{HNO}_{3}$ or $\mathrm{KOH}$. The suspensions were shaken for $20-24 \mathrm{~h}$ at room temperature $\left(20 \pm 2{ }^{\circ} \mathrm{C}\right)$. Then the solid samples were separated by centrifugation and then the supernatants were further filtrated through $0.45 \mu \mathrm{m}$ filters. The remaining concentration of phosphate was determined by the molybdenum blue method [15]

\section{Results and discussion}

\subsection{Characterization of the aluminum (hydr)oxides}

As shown in Fig. 1, the XRD patterns indicated that the two samples used in this study represented two different typical aluminum (hydr)oxide structures, i.e. pseudo-boehmite and lowcrystalline $\alpha$-alumina (labeled as alumina-A). Boehmite has a layer structure similar to $\gamma-\mathrm{FeOOH}$, consisting of linked chains of $\mathrm{AlO}_{6}$ octahedra, which run parallel to the $c$-axis, forming an infinite two-dimensional sheet [16]. Pseudo-boehmite is a kind of low-crystalline boehmite, distinguished by the broadened XRD diffraction peaks and large specific surface area [17]. The sharp peaks in the XRD pattern (Fig. 1) of alumina-A confirmed the existence of $\alpha-\mathrm{Al}_{2} \mathrm{O}_{3}$, and the stretched peaks should be ascribed to $\gamma-\mathrm{Al}_{2} \mathrm{O}_{3}$ phase. $\gamma-\mathrm{Al}_{2} \mathrm{O}_{3}$ is a transition phase of the most stable $\alpha$-alumina in the dehydrating process of the aluminum hydroxides. Both aluminum oxide materials used in this study were low-crystalline. It has been reported

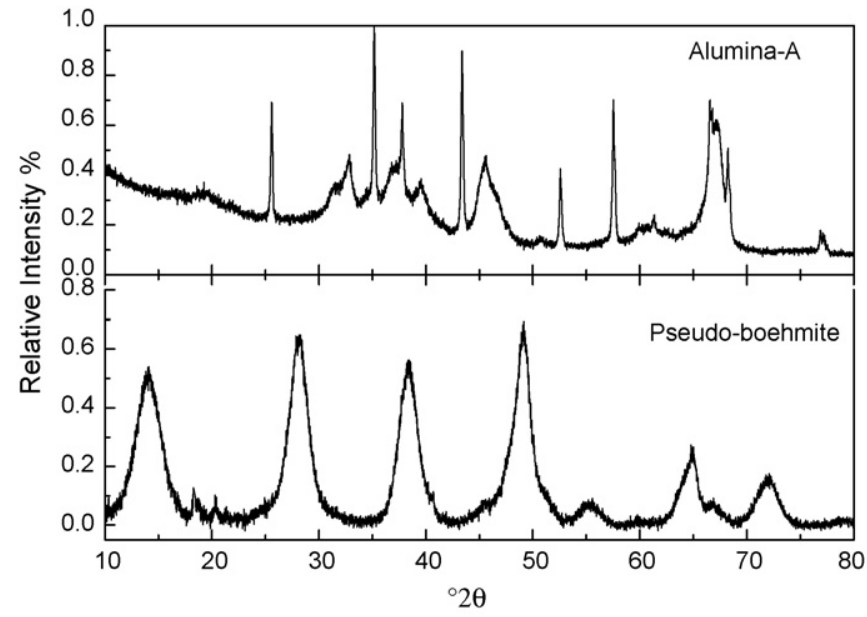

Fig. 1. XRD patterns of two aluminum oxide materials. 

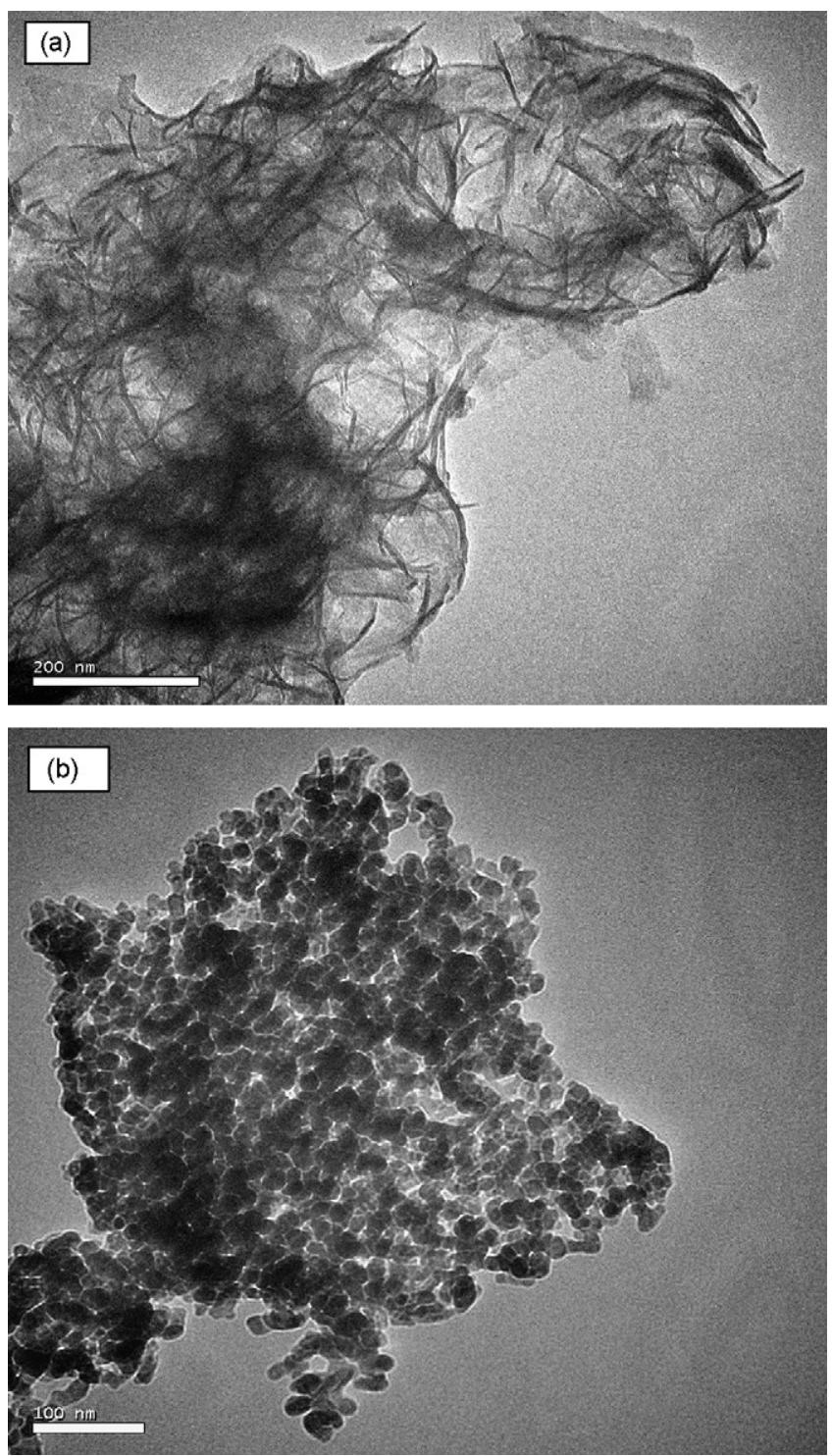

Fig. 2. TEM images for two samples: (a) pseudo-boehmite and (b) alumina-A.

that low-crystalline aluminum oxide usually have larger specific surface area (small particle size) and higher surface activity than well-crystalline aluminum (hydr)oxides [18]. The external specific surface areas of pseudo-boehmite and $\alpha$-alumina measured by the BET/ $\mathrm{N}_{2}$ method were about 166 and $89 \mathrm{~m}^{2} \mathrm{~g}^{-1}$, respectively.

The apparent particle size distribution $\left(d_{50 \%}\right)$ of pseudoboehmite and alumina-A in water was about 6.37 and $1.58 \mu \mathrm{m}$, respectively.

The TEM images (Fig. 2) showed that the pseudo-boehmite appeared as polycrystalline lamella and the alumina-A was in spherical shape, and both existed as agglomerates of nanoparticles. From the TEM images, it is obvious that the size of both pseudo-boehmite and alumina-A were on the nano-scale, which accounted for their large specific surface area.

The isoelectric points (iep) of the two aluminum oxide particles in the $\mathrm{KNO}_{3}$ solution were at $9.5 \pm 0.1$ (Fig. 3). The results of the solubility experiments in $\mathrm{KNO}_{3}$ solutions as medium are

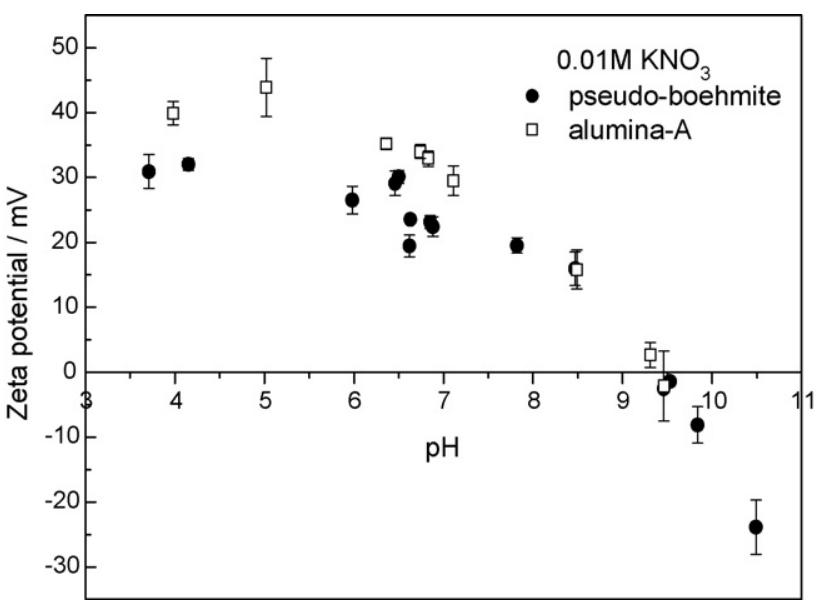

Fig. 3. The zeta-potential of aluminum oxide particles in $0.01 \mathrm{M} \mathrm{KNO}_{3}$ solution.

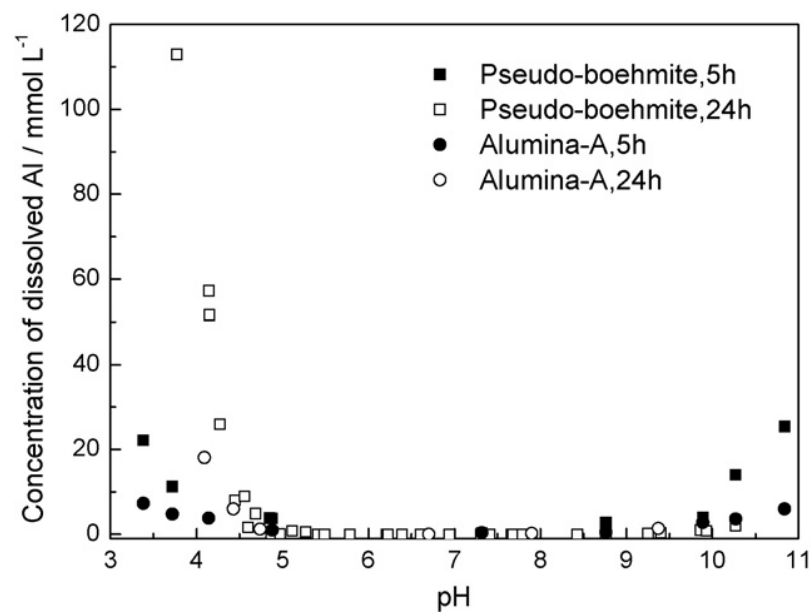

Fig. 4. The total concentration of dissolved aluminum from pseudo-boehmite and alumina-A after $5 \mathrm{~h}\left(2 \mathrm{~g} \mathrm{~L}^{-1}\right)$ and $24 \mathrm{~h}\left(4 \mathrm{~g} \mathrm{~L}^{-1}\right)$ of contact with $0.01 \mathrm{M}$ $\mathrm{KNO}_{3}$ solution.

shown in Fig. 4. Obviously, that the solubility of alumina oxides was a function of $\mathrm{pH}$ and contact time.

The physicochemical properties parameters of the two alumina oxides were summarized in Table 1 .

\subsection{Potentiometric titrations}

The surface charge, $Q_{\mathrm{H}}\left(\mathrm{mol} \mathrm{L}^{-1}\right)$, was calculated directly from the measured $\mathrm{pH}$ and the amount of acid or base added at each data point $[9,10]$ as follows:

$Q_{\mathrm{H}}=C_{\mathrm{A}}-C_{\mathrm{B}}-\left[\mathrm{H}^{+}\right]_{\text {meas }}+\left[\mathrm{OH}^{-}\right]_{\text {meas }}$

Table 1

Physicochemical properties for the two samples investigated

\begin{tabular}{lll}
\hline & Pseudo-boehmite & Alumina-A \\
\hline Compound name & Pseudo-boehmite & Active alumina \\
Crystal structure & $\gamma$-AlOOH & $\gamma$-/ $\alpha$-Alumina \\
Chemical formula & $\mathrm{Al}_{2} \mathrm{O}_{3} \cdot \mathrm{H}_{2} \mathrm{O}$ & $\mathrm{Al}_{2} \mathrm{O}_{3}$ \\
Particle size distribution $(d(0.5))(\mu \mathrm{m})$ & 6.372 & 1.584 \\
BET-SSA $\left(\mathrm{m}^{2} \mathrm{~g}^{-1}\right)$ & 166 & 89 \\
\hline
\end{tabular}



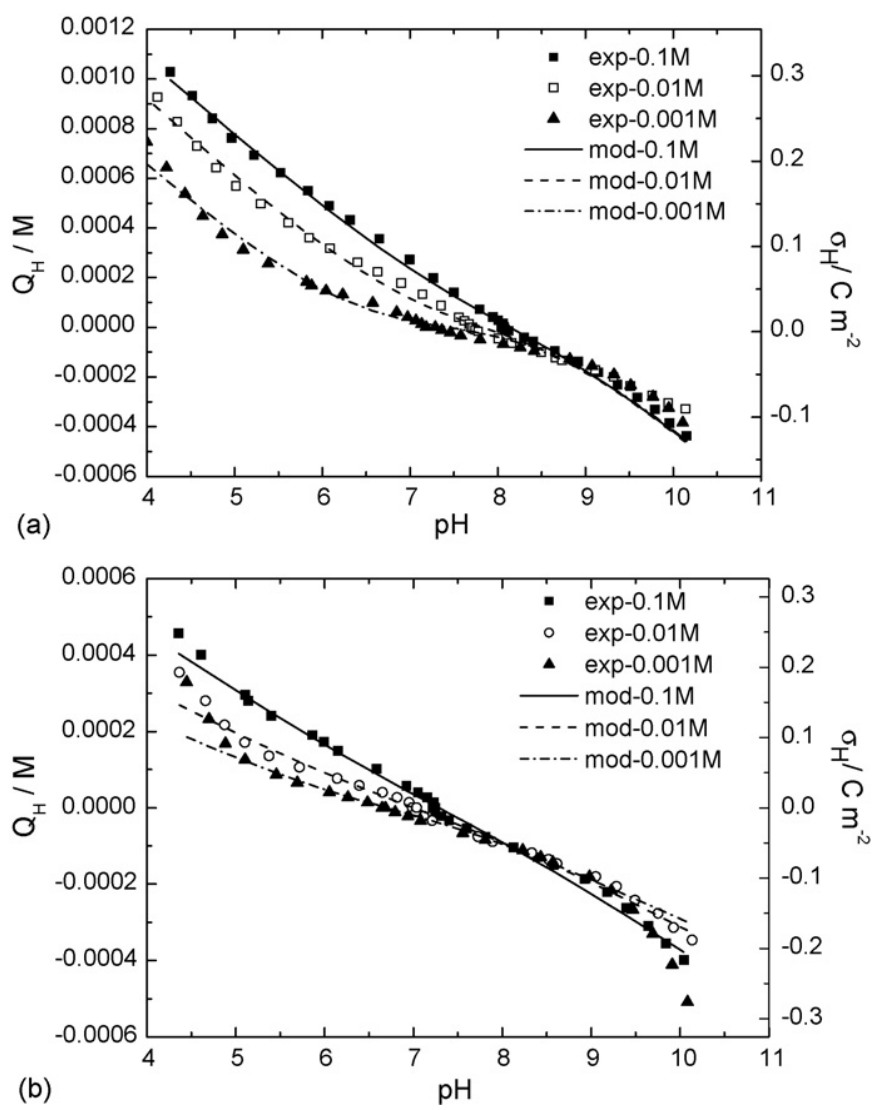

Fig. 5. Experimental surface net proton charge vs. pH curves from the two-side titrations. Data were fitted according to the 2pK-CCM (Constant Capacitance Model): (a) pseudo-boehmite and (b) alumina-A. The results from the model are shown as lines (full or dashed).

where $C_{\mathrm{A}}$ and $C_{\mathrm{B}}\left(\mathrm{mol} \mathrm{L}^{-1}\right)$ were the concentrations of acid and base added to the suspension, respectively. Since the titration procedure was finished within $5 \mathrm{~h}$ and in the moderate $\mathrm{pH}$ domain (4-10), the dissolution of the samples were negligible (Fig. 4).

Fig. 5 shows experimental surface proton charge versus $\mathrm{pH}$ curves at different $\mathrm{KNO}_{3}$ electrolyte concentrations. For the $\mathrm{pH}$ range investigated, the surface charge increased with the increase of ionic strength. This is because the increased electrolyte concentration pressed the double layer thickness and reduced the electrostatic repulsion at the surface, resulting in an increased proton adsorption.

In this article, the classical 2pK-CCM surface complexation model was used to describe the surface proton charge and to calculate the surface acidity constant and surface site density of the two aluminum oxides [19]. The proton affinity constants and site density were optimized by adjusting the capacitance of the interface, and the fitting parameters were summarized in Table 2. It can be seen from Fig. 5 and Table 2, that the classical 2pK-CCM approach could be used to describe the charging behavior of both samples. The average surface site density of pseudo- $\gamma$-AlOOH $\left(16.2 \mu \mathrm{mol} \mathrm{m}^{-2}\right)$ was greater than for alumina-A $\left(11.5 \mu \mathrm{mol} \mathrm{m} \mathrm{m}^{-2}\right)$. The surface acidity could be evaluated from the $\mathrm{p} K_{\mathrm{a}}$ value of the surface protonation. The $\mathrm{p} K_{\mathrm{a} 1}$ value was $5.68 \pm 0.54$ for boehmite and $5.38 \pm 0.40$ for alumina-A. Therefore, the acidity order of the surface hydroxyls was alumina-A $>$ pseudo- $\gamma$-AlOOH.

The difference in surface acidity reflects the difference in surface chemical composition of various aluminum hydroxides and oxides. Accordingly, different aluminol groups $(\equiv \mathrm{AlOH}$, $\equiv \mathrm{Al}_{2} \mathrm{OH}, \equiv \mathrm{O}_{2} \mathrm{AlOH}$ ) might exist at the hydrated alumina surfaces, where the aluminum ions are the resources of acidity and oxygen ions contribute to the alkalinity. That is to say, the alumina-A surface had hydroxyl groups that were slightly more polarized than hydroxyls on the alumina hydroxide surface, because of the differences in coordination number of the aluminum ions [20]. Therefore, it could be expected that the more acidic surfaces of alumina-A would exhibit stronger anion affinity.

\subsection{Phosphate adsorption experiments}

Fig. 6a and $\mathrm{b}$ shows the adsorption isotherms of phosphate in $0.01 \mathrm{M} \mathrm{KNO}_{3}$ solution at $\mathrm{pH} 4$ and 6 . The linear expression of the Langmuir isotherm was employed to quantitatively describe the adsorption process:

$\frac{[\mathrm{P}]}{[\mathrm{AlOH}-\mathrm{P}]}=\frac{1}{[\mathrm{AlOH}]_{\mathrm{T}} K}+\frac{[\mathrm{P}]}{[\mathrm{AlOH}]_{\mathrm{T}}}$

where $[\mathrm{AlOH}-\mathrm{P}]$ is the concentration of adsorbed phosphate species, $[\mathrm{AlOH}]_{\mathrm{T}}$ represents the saturated amount of adsorption $\left(\Gamma_{\mathrm{m}}\right),[\mathrm{P}]$ the equilibrium concentration of phosphate in solution,

Table 2

Surface characteristic parameters of two different kinds of aluminum oxides in $\mathrm{KNO}_{3}$ solution, as obtained by FITEQL program

\begin{tabular}{|c|c|c|c|c|c|c|c|}
\hline & $I(\mathrm{M})$ & $\begin{array}{l}\text { Capacitance } \\
\left(\mathrm{F} \mathrm{m}^{-2}\right)\end{array}$ & $N_{\mathrm{s}}\left(\times 10^{-4} \mathrm{~mol} \mathrm{~m}^{-2}\right)$ & $\mathrm{p} K_{\mathrm{a} 1}^{\mathrm{int}}$ & $\mathrm{p} K_{\mathrm{a} 2}^{\mathrm{int}}$ & WSOS/DF & $\mathrm{PZC}^{\mathrm{a}}$ \\
\hline \multirow{4}{*}{ Pseudo-boehmite $(\gamma$-AlOOH $)$} & 0.1 & 1.77 & 0.256 & 6.17 & 10.10 & 24.51 & 8.14 \\
\hline & 0.01 & 1.66 & 0.134 & 5.77 & 9.89 & 71.28 & 7.83 \\
\hline & 0.001 & 1.93 & 0.095 & 5.10 & 9.76 & 71.77 & 7.43 \\
\hline & & & $0.162 \pm 0.084$ & $5.68 \pm 0.54$ & $9.9 \pm 0.17$ & & $7.8 \pm 0.36$ \\
\hline \multirow{4}{*}{ Alumina-A $\left(\alpha-\mathrm{Al}_{2} \mathrm{O}_{3}\right)$} & 0.1 & 1.71 & 0.148 & 5.81 & 8.76 & 35.32 & 7.29 \\
\hline & 0.01 & 1.35 & 0.120 & 5.30 & 8.71 & 39.47 & 7.01 \\
\hline & 0.001 & 1.23 & 0.078 & 5.03 & 8.38 & 48.44 & 6.71 \\
\hline & & & $0.115 \pm 0.035$ & $5.38 \pm 0.40$ & $8.62 \pm 0.21$ & & $7.0 \pm 0.29$ \\
\hline
\end{tabular}

\footnotetext{
${ }^{\mathrm{a}} \mathrm{PZC}=(1 / 2)\left(\mathrm{p} K_{\mathrm{a} 1}^{\mathrm{int}}+\mathrm{p} K_{\mathrm{a} 2}^{\mathrm{int}}\right)$.
} 

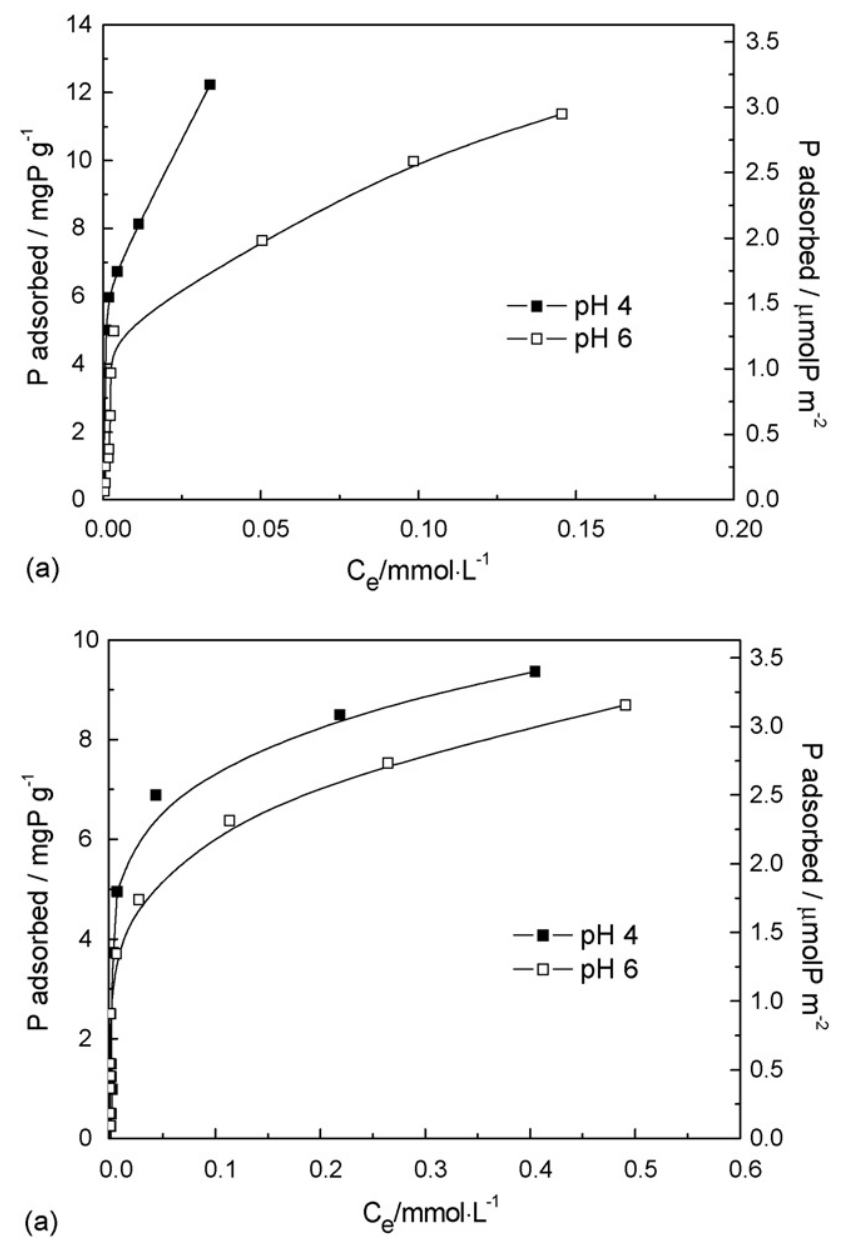

Fig. 6. Phosphate adsorption on aluminum (hydr)oxides in $0.01 \mathrm{M} \mathrm{KNO}_{3}$ at $\mathrm{pH}$ 4 and 6: (a) pseudo-boehmite and (b) alumina-A.

and $K$ is the Langmuir isotherm constant. The Langmuir constant $K$ reflects the interaction between surface and the absorbates, and the $\Gamma_{\mathrm{m}}$ is a measure of adsorption capacity.

Table 3 presented the parameters of the Langmuir isotherms. By comparing the $\Gamma_{\mathrm{m}}$ values, it could be found that at both $\mathrm{pH} 4$ and 6, the adsorption capacities of pseudo- $\gamma$-AlOOH were higher than those of $\alpha-\mathrm{Al}_{2} \mathrm{O}_{3}$. The higher adsorption capacity of pseudo- $\gamma$-AlOOH could be attributed to its larger specific surface area.

However, it was noted that the adsorption capacities of pseudo- $\gamma$-AlOOH were about 1.4 times the values obtained for alumina-A at $\mathrm{pH} 4$ and 6 although the specific surface area of pseudo- $\gamma$-AlOOH was almost twice as large as the surface area for alumina-A. These results indicated an adsorption affinity dif-

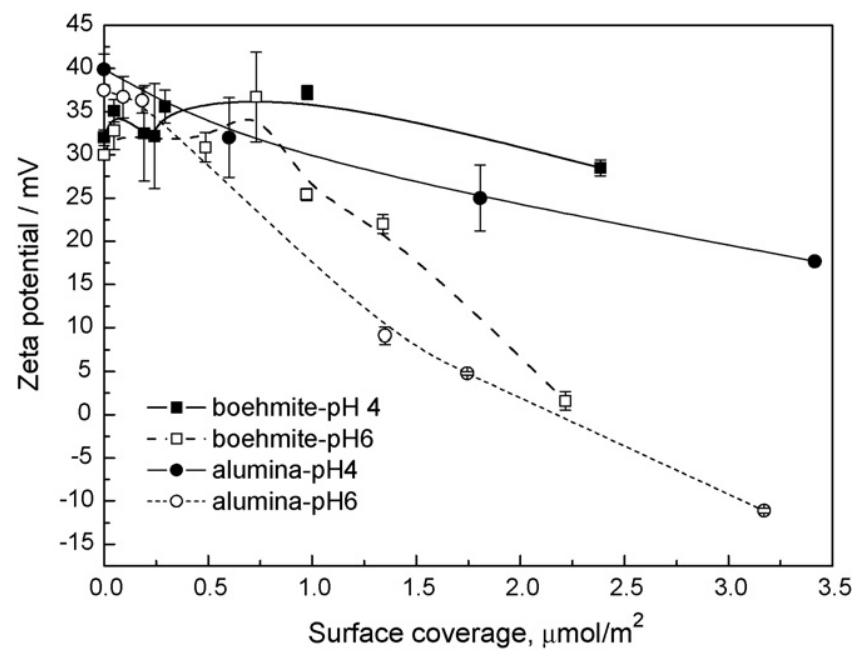

Fig. 7. Zeta-potential of pseudo-boehmite and alumina-A vs. phosphate surface overage at $\mathrm{pH} 4$ and 6.

ference between the two materials. Such a difference could be reflected by the adsorption density. The adsorption density was calculated, according to the equation:

$\Gamma_{\mathrm{d}}=\frac{\Gamma_{\mathrm{m}}}{A}\left(\mu \mathrm{mol} \mathrm{m}^{-2}\right)$

where $A$ is the specific surface area $\left(\mathrm{m}^{2} \mathrm{~g}^{-1}\right)$, and $\Gamma_{\mathrm{m}}$ is the saturated amount of adsorption calculated from the Langmuir isotherms. Then it can be found that at $\mathrm{pH} \mathrm{4}$, the adsorption density of alumina-A was $3.42 \mu \mathrm{mol} \mathrm{m}^{-2}$, and that of pseudo-boehmite was $2.65 \mu \mathrm{mol} \mathrm{m}^{-2}$. At $\mathrm{pH} 6$, the adsorption density of alumina-A was also greater than that of pseudoboehmite (Table 3), which suggested that the surface hydroxyls of $\alpha-\mathrm{Al}_{2} \mathrm{O}_{3}$ had greater reactivity than surface hydroxyls of pseudo- $\gamma$-AlOOH. This difference was possibly resulting from the relatively more acidic surface of $\alpha-\mathrm{Al}_{2} \mathrm{O}_{3}$, as reflected by its lower $\mathrm{p} K_{\mathrm{a}}$ value.

This reactivity difference could also be confirmed by zeta-potential change after phosphate adsorption. When the zeta-potential of the two aluminum oxides is plotted against phosphate surface coverage at $\mathrm{pH} 4$ and 6 (Fig. 7), it can be seen that the zeta-potential of the surface decreased with the increase of phosphate coverage for both aluminum oxides. However, the zeta-potential of $\alpha-\mathrm{Al}_{2} \mathrm{O}_{3}$ decreased more rapidly with the surface coverage while the potential for pseudo-boehmite changed much less especially at low surface coverage. Although the mechanism of phosphate bonding was assumed to be similar for both the aluminum oxides, the different phosphate adsorption affinity may be explained by the distinctive surface structure

Table 3

Langmuir isotherm parameters for adsorption of phosphate on two aluminum oxides

\begin{tabular}{|c|c|c|c|c|c|c|c|c|}
\hline \multirow[t]{2}{*}{ Sample } & \multicolumn{4}{|l|}{ pH 4} & \multicolumn{4}{|l|}{ pH 6} \\
\hline & $\overline{\Gamma_{\mathrm{m}}\left(\mathrm{mg} \mathrm{g}^{-1}\right)}$ & $\Gamma_{\mathrm{d}}\left(\mu \mathrm{mol} \mathrm{m}{ }^{-2}\right)$ & $K$ & $R^{2}$ & $\overline{\Gamma_{\mathrm{m}}\left(\mathrm{mg} \mathrm{g}^{-1}\right)}$ & $\Gamma_{\mathrm{d}}\left(\mu \mathrm{mol} \mathrm{m}{ }^{-2}\right)$ & $K$ & $R^{2}$ \\
\hline Pseudo-boehmite & 13.59 & 2.65 & 9.80 & 0.858 & 11.83 & 2.31 & 2.38 & 0.976 \\
\hline Alumina-A & 9.41 & 3.42 & 3.38 & 0.997 & 8.54 & 3.11 & 2.86 & 0.990 \\
\hline
\end{tabular}

The adsorption capacity $\Gamma_{\mathrm{m}}$ is expressed as $\mathrm{mg}_{\mathrm{p}}$ phosphorus $\mathrm{g}^{-1}$ of the aluminum oxide. 
of the adsorbents. For $\alpha-\mathrm{Al}_{2} \mathrm{O}_{3}$, the surface hydroxyls have higher Lewis acidity, and the formation of inner-sphere surface complexes by ligand-exchange reactions predominate. For pseudo-boehmite, electrostatic interactions play a more prominent role, especially at low $\mathrm{pH}$. Thus it could be inferred that the binding of phosphate to $\alpha-\mathrm{Al}_{2} \mathrm{O}_{3}$ was stronger than its bonding to pseudo-boehmite.

From Fig. 6 and Table 3, it can also be seen that for both pseudo- $\gamma-\mathrm{AlOOH}$ and $\alpha-\mathrm{Al}_{2} \mathrm{O}_{3}$, the adsorbed amount of phosphate at $\mathrm{pH} 4$ was higher than that at $\mathrm{pH}$ 6. This can be explained from two aspects, adsorbents and absorbates, since the $\mathrm{pH}$ value can affect both the phosphate species and the surface hydroxyl species. In terms of absorbates, the distribution of major solution-phosphate species versus $\mathrm{pH}$ could be calculated by using the $\mathrm{H}_{3} \mathrm{PO}_{4}$ dissociation constants $\left(\mathrm{p} K_{\mathrm{a} 1}=2.15\right.$, $\left.\mathrm{p} K_{\mathrm{a} 2}=9.35, \mathrm{p} K_{\mathrm{a} 3}=21.7\right)$ [21]. It can be seen from Fig. 8a that the $\mathrm{H}_{2} \mathrm{PO}_{4}{ }^{-}$ions are predominating at $\mathrm{pH} 3-6$, and in the high $\mathrm{pH}$ range, the $\mathrm{HPO}_{4}{ }^{2-}$ ions are dominating. At $\mathrm{pH} 4$, the fraction of $\mathrm{H}_{2} \mathrm{PO}_{4}{ }^{-}$is $98.5 \%$, and at $\mathrm{pH} 6$, it is $94.1 \%$. Chubar et al. [22] have suggested that the $\mathrm{H}_{2} \mathrm{PO}_{4}{ }^{-}$species were more easily adsorbed on metal (hydr)oxide surfaces than $\mathrm{HPO}_{4}{ }^{2-}$ species.
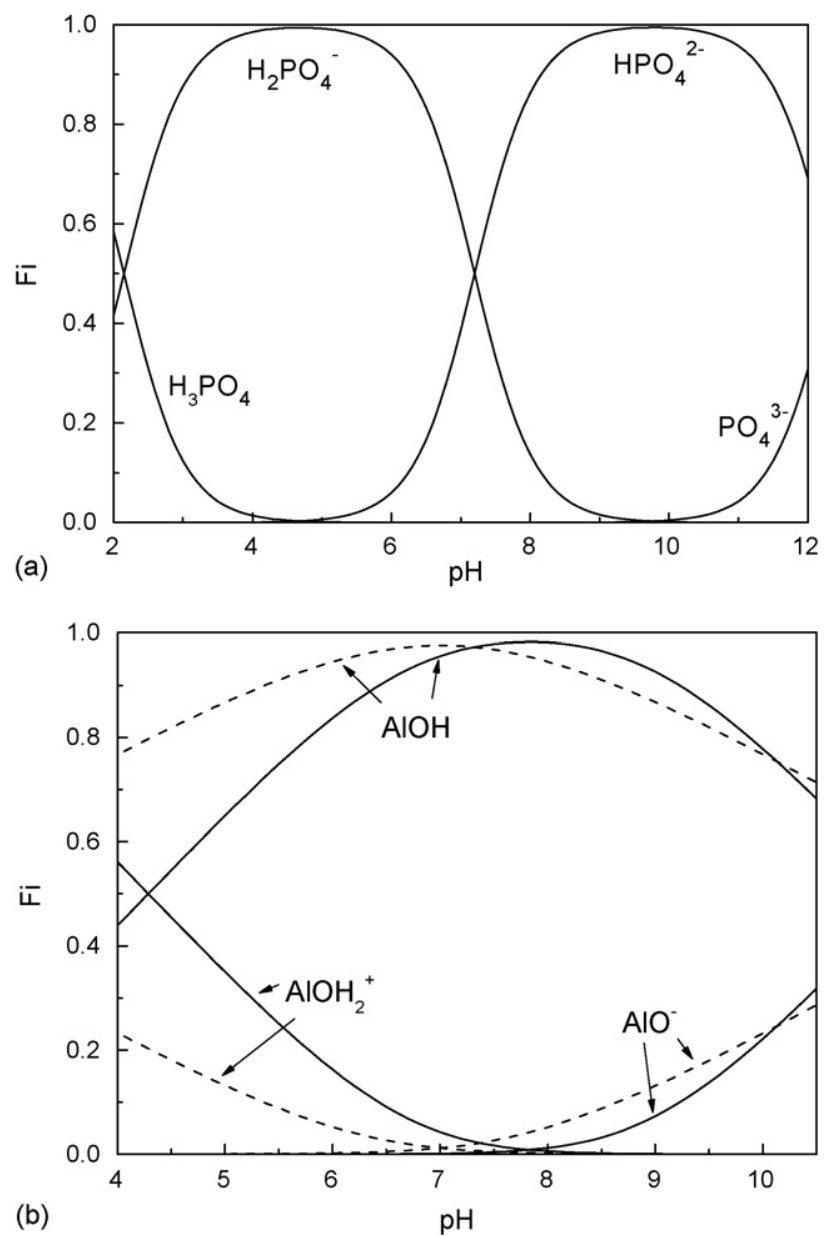

Fig. 8. Speciation distribution diagrams of phosphate (a) and aluminum oxide (pseudo-boehmite and alumina-A) surface species (b) as a function of $\mathrm{pH}$. The thick lines represents pseudo-boehmite and the dashed lines denoted alumina-A. $I=0.01 \mathrm{M} \mathrm{KNO}_{3},\left[\mathrm{H}_{3} \mathrm{PO}_{4}\right]_{\mathrm{TOT}}=[\equiv \mathrm{AlOH}]_{\mathrm{TOT}}=1.0 \mathrm{mM}$.
According to the $\mathrm{p} K_{\mathrm{a}}$ values determined from titration curves, the surface species distribution versus $\mathrm{pH}$ of the two alumina (hydr)oxides could be calculated using the WinSGW program (Fig. 8b) [23]. It can be seen from the figure that at $\mathrm{pH} 4$ the fraction of $\equiv \mathrm{AlOH}_{2}{ }^{+}$species on pseudo-boehmite was greater than on alumina-A while at $\mathrm{pH} 6$ the concentration of $\equiv \mathrm{AlOH}_{2}{ }^{+}$ species decreased and the $\equiv \mathrm{AlOH}$ species became dominating. Thus at $\mathrm{pH} 4$, the surface with more positive charge could adsorb more anions.

\section{Conclusion}

Based on the investigation of phosphate adsorption on two characterized aluminum (hydr)oxides with different crystal structure, pseudo-boehmite and low-crystalline $\alpha-\mathrm{Al}_{2} \mathrm{O}_{3}$, the following conclusions can be obtained:

(i) Due to the sheeted polycrystalline-fiber morphology, pseudo-boehmite had a larger specific surface area $\left(166 \mathrm{~m}^{2} \mathrm{~g}^{-1}\right)$, and was more soluble in acidic $\mathrm{pH}$ than alumina-A and its solubility increased dramatically when solution $\mathrm{pH}$ was below 4 .

(ii) Alumina-A, a low-crystalline $\alpha-\mathrm{Al}_{2} \mathrm{O}_{3}$, was more acidic than pseudo-boehmite. The surface acidity constants $\left(\mathrm{p} K_{\mathrm{a} 1}\right.$ and $\mathrm{p} K_{\mathrm{a} 2}$ ) for alumina-A was between 5.03-5.81 and 8.38-8.76 and for pseudo-boehmite they were between 5.10-6.17 and 9.76-10.10, depending on ionic strength.

(iii) Phosphate adsorption on the surface of tested alumina samples at acidic pH (4-6) exhibited a Langmuir type of adsorption isotherm. The results from the adsorption isotherms showed that at both $\mathrm{pH} 4$ and 6, pseudo- $\gamma$ $\mathrm{AlOOH}$ had a larger adsorption capacity than alumina-A, while alumina-A had a greater adsorption reactivity than pseudo- $\gamma-\mathrm{AlOOH}$. This could be explained by the difference between surface hydroxyls originating from different crystal structures.

\section{Acknowledgement}

The authors would like to thank Dr. Shi Baoyou, at the Research Center For Eco-Environmental Sciences, and Dr. Allan Holmgren, at the Department of Chemical Engineering and Geosciences, Lulea University of Technology, for correcting the English of the manuscript. This work was supported by the National Natural Science Foundation of China (Grant No. 20537020). The kind suggestion and comments from the anonymous reviewers are greatly appreciated.

\section{References}

[1] B. Kasprzyk-Hordern, Chemistry of alumina, reactions in aqueous solution and its application in water treatment, Adv. Colloid Interf. 19 (2004) 19-48.

[2] P.W. Schindler, Surface complexes at oxide-water interfaces, in: M.A. Anderson, A.J. Rubin (Eds.), Adsorption of Inorganics at Solid-Liquid Interfaces, Ann Arbor Publishers Inc., Michigan, 1981, pp. 1-50.

[3] L. Madsen, A.M. Blokhus, Adsorption of benzoic acid on $\alpha$-alumina and $\gamma$-boehmite, J. Colloid Interf. Sci. 166 (1994) 259-262. 
[4] P. Persson, J. Nordin, J. Rosenqvist, et al., Comparison of the adsorption of $o$-phthalate on boehmite $(\gamma-\mathrm{AlOOH})$, aged $\gamma-\mathrm{Al}_{2} \mathrm{O}_{3}$, and goethite $(\alpha-$ FeOOH), J. Colloid Interf. Sci. 206 (1998) 252-266.

[5] Y.S.R. Chen, J.N. Butler, W. Stumm, Kinetic study of phosphate reaction with aluminum oxide and kaolinite, Environ. Sci. Technol. 7 (1973) 327-332.

[6] C.P. Huang, Adsorption of phosphate at the hydrous $\gamma-\mathrm{Al}_{2} \mathrm{O}_{3}$ electrolyte interface, J. Colloid Interf. Sci. 53 (1975) 178-186.

[7] L. Lijklema, Interaction of orthophosphate with iron(1 11 ) and aluminum hydroxides, Environ. Sci. Technol. 14 (1980) 537-541.

[8] W.H. van Riemsdijk, J. Lyklema, Reaction of phosphate with gibbsite $\left(\mathrm{Al}(\mathrm{OH})_{3}\right)$ beyond the adsorption maximum, J. Colloid Interf. Sci. 76 (1980) 55-66.

[9] C. Toy, O.J. Whittemore, Phosphate bonding with several calcined aluminas, Ceram. Int. 15 (1989) 167-171.

[10] S. Tanada, M. Kabayama, N. Kawasaki, et al., Removal of phosphate by aluminum oxide hydroxide, J. Colloid Interf. Sci. 257 (2003) 135-140.

[11] W. Stumm, Chemistry of the Solid-Water Interface: Processes at the Mineral-water and Particle-water Interface in Natural Systems, Wiley, New York, 1992.

[12] D.A. Dzombak, F.M.M. Morel, Surface Complexation Modeling: Hydrous Ferric Oxide, Wiley, New York, 1990.

[13] J. Rosenqvist, P. Persson, S. Sjoberg, Protonation and charging of nanosized gibbsite $\left(\alpha-\mathrm{Al}(\mathrm{OH})_{3}\right)$ particles in aqueous suspension, Langmuir 18 (2002) 4598-4604.
[14] T. Hiemstra, H. Yong, W.H. van Riemsdijk, Interfacial charging phenomena of aluminum (hydr)oxides, Langmuir 15 (1999) 5942-5955.

[15] J. Murphy, J.P. Riley, A modified single solution method for the determination of phosphate in natural water, Anal. Chim. Acta 27 (1962) 31-36.

[16] G.G. Christoph, C.E. Corbato, D.A. Hofmann, R.T. Tettenhorst, The crystal structure of boehmite, Clays Clay Miner. 27 (1979) 81-86.

[17] B.C. Lippens, J.J. Steggerda, Active alumina, in: B.G. Linsen (Ed.), Physical and Chemical Aspects of Adsorbents and Catalysts, Academic Press, New York, 1970 (Chapter 4).

[18] C. Morterra, G. Magnacca, A case study: surface chemistry and surface structure of catalytic aluminas, as studied by vibrational spectroscopy of adsorbed species, Catal. Today 27 (1996) 497-532.

[19] Q. Du, Z.X. Sun, W. Forsling, et al., Acid-base properties of aqueous illite surfaces, J. Colloid Interf. Sci. 187 (1997) 221-231.

[20] W.J. Wnek, R. Davies, An analysis of the dependence of the zeta potential and surface charge on surfactant concentration, ionic strength, and $\mathrm{pH}, \mathrm{J}$ Colloid Interf. Sci. 60 (1977) 361-375

[21] W.F. Bleam, P.E. Pfeffer, S. Goldberg, A ${ }^{31} \mathrm{P}$ solid-state nuclear magnetic resonance study of phosphate adsorption at the boehmite/aqueous solution interface, Langmuir 7 (1991) 1702-1712.

[22] N.I. Chubar, V.A. Kanibolotskyy, V.V. Strelko, et al., Adsorption of phosphate ions on novel inorganic ion exchangers, Colloid Surf. A 255 (2005) $55-63$.

[23] J. Lindgren, M. Karlsson, The WinSGW Program, Umeå University, Sweden, 2002. 